\title{
Controle valorativo dos atos de autonomia praticados por pessoas com deficiência intelectual ou psíquica
}

\author{
Valuable control of acts of autonomy practiced by psychically or intellectually \\ disabled person
}

\author{
Ana Carolina Brochado Teixeira* \\ Livia Teixeira Leal ${ }^{\star *}$
}

\section{Resumo}

\begin{abstract}
O presente estudo tem por objetivo analisar os reflexos do Estatuto da Pessoa com Deficiência sobre o regime das incapacidades e consequentemente sobre a teoria das invalidades, buscando uma análise funcional, que compatibilize a exclusão das pessoas com deficiência intelectual ou psíquica dos arts. $3^{\circ}$ e $4^{\circ}$ do Código Civil de 2002 com as finalidades da Lei Brasileira de Inclusão. Propõe-se que o intérprete module a invalidação do ato, diante da situação concretamente analisada, a partir da verificação do grau de vulnerabilidade e discernimento em concreto da pessoa com deficiência intelectual ou psíquica no momento da prática do ato, bem como se o ato e seus efeitos atendem ou não aos valores do ordenamento, realizando-se um controle de merecimento de tutela.
\end{abstract}

Palavras-chave: Capacidade civil. Pessoa com Deficiência. Autonomia. Invalidade.

\section{Abstract}

The purpose of this study is to analyze the reflexes of the Disability Statute on the disability system and consequently on the theory of disability, seeking a functional analysis that makes the exclusion of psychically or intellectually disabled person from arts. 3 and 4 of the Civil Code of 2002 compatible with the purposes of the Brazilian Inclusion Law. It is proposed that the interpreter modifies the invalidation of the act, in view of the situation specifically analyzed, based on the verification of the degree of vulnerability and specific discernment of the person with intellectual or mental disability at the time of the practice of the act, as well as if the act and its effects comply with the legal values, making an evaluation of lawfulness.

Keywords: Legal capacity. Disabled person. Autonomy. Invalidity.

\section{Introdução: As modificações implementadas pelo Estatuto da Pessoa com Deficiência (EPD) - Lei n. ${ }^{0} 13.146 / 2015$}

Objeto de elogios e críticas, o Estatuto da Pessoa com Deficiência (EPD), Lei n. ${ }^{\circ}$ 13.146/2015, foi editado com o objetivo de integrar ao sistema infraconstitucional brasileiro as orientações da Convenção Internacional sobre os Direitos das Pessoas com Deficiência, incorporada pelo Brasil por meio do Decreto n. ${ }^{\circ}$ 6.949/2009. Aprovada nos termos do art. $5^{\circ}$, $\S 3^{\circ}$, da Constituição da República de 1988 , a Convenção já possuía caráter constitucional, mas até então não havia uma efetiva regulamentação legal que efetivasse os seus preceitos.

Como princípios gerais, a Convenção contempla em seu artigo $3^{\circ}$ o respeito pela dignidade, a autonomia e a independência das pessoas, inclusive no que se refere à liberdade de fazer as próprias escolhas. Em

Doutora em Direito Civil pela UERJ. Mestre em Direito Privado pela PUC/MG. Especialista em Diritto Civile pela Università degli Studi di Camerino, Itália. Professora de Direito Civil do Centro Universitário UNA. Coordenadora editorial da RBDCivil. Pesquisadora do CEBID. Advogada. Belo Horizonte - MG - Brasil. E-mail: anacarolina@tmg.adv.br.

Doutoranda e Mestre em Direito Civil pela Universidade do Estado do Rio de Janeiro - UERJ. Pós-Graduada pela Escola da Magistratura do Estado do Rio de Janeiro - EMERJ. Professora convidada da PUC-Rio, da EMERJ e da ESAP. Assessora no Tribunal de Justiça do Rio de Janeiro - TJRJ. Rio de Janeiro - RJ - Brasil. E-mail: livialealuerj@gmail.com. 
seu artigo 12.2, ressalta a necessidade de as pessoas com deficiência gozarem de capacidade legal em igualdade de condições com as demais pessoas em todos os aspectos da vida. ${ }^{1}$

Com base nessas orientações, determina o EPD, em seu art. $6^{\circ}$, que a "deficiência não afeta a plena capacidade civil da pessoa" e, em seu art. 84, que a pessoa com deficiência "tem assegurado o direito ao exercício de sua capacidade legal em igualdade de condições com as demais pessoas", estabelecendo a curatela como medida excepcional e restrita a atos patrimoniais e negociais, que apenas deve ser determinada em prol do próprio curatelado. ${ }^{2}$

Assim, busca o legislador afastar a lógica que se tinha até então, a respeito da curatela como uma interdição quase absoluta de direitos, para considerar o sujeito e suas peculiaridades individuais e sociais, promovendo um verdadeiro redimensionamento do instituto, que passa a ser funcionalizado ao melhor interesse do curatelado de forma mais efetiva pela normativa vigente. ${ }^{3}$

Cabe observar que o art. $2^{\circ}$ do EPD define a pessoa com deficiência como aquela que possui "impedimento de longo prazo de natureza física, mental, intelectual ou sensorial, o qual, em interação com uma ou mais barreiras, pode obstruir sua participação plena e efetiva na sociedade em igualdade de condições com as demais pessoas". Há, nesse contexto, uma preocupação com a eliminação de barreiras para a participação plena da pessoa com deficiência na sociedade, buscando-se retirar eventuais obstáculos, inclusive legais, para que se opere essa inclusão na prática.

Nessa seara, é importante lembrar que há um histórico de tratamentos excludentes em relação àqueles que não se encaixam nos padrões de normalidade estabelecidos socialmente. As religiões tiveram um papel significativo nesse processo, seja do Mundo Antigo, com as práticas eugênicas presentes em Roma e na Grécia Antiga, ${ }^{4}$ seja na Idade Média, por meio da marginalização daqueles que destoavam do estabelecido pela Igreja Católica. Com o advento do lluminismo, a partir do final do século XVIII, o movimento de segregação se operou com o respaldo do argumento científico, exercendo a medicina psiquiátrica importante papel nesse processo. ${ }^{5}$

A pessoa com deficiência intelectual ou psíquica era considerada, em tal contexto, um ser doente, que deveria receber intervenção médica. Contudo esse tratamento estava profundamente atrelado a um viés discriminatório, que segregava tais pessoas da participação da vida social. Essa visão foi incorporada pelo Código Civil de 1916, que reconhecia como absolutamente incapazes os denominados loucos de todo o gênero (art. $\left.5^{\circ}, 11\right) .^{6}$

"Artigo 3 - Princípios gerais. Os princípios da presente Convenção são: a) O respeito pela dignidade inerente, a autonomia individual, inclusive a liberdade de fazer as próprias escolhas, e a independência das pessoas; (...)".

"Artigo 12 - Reconhecimento igual perante a lei. 1. Os Estados Partes reafirmam que as pessoas com deficiência têm o direito de ser reconhecidas em qualquer lugar como pessoas perante a lei. 2. Os Estados Partes reconhecerão que as pessoas com deficiência gozam de capacidade legal em igualdade de condições com as demais pessoas em todos os aspectos da vida. 3. Os Estados Partes tomarão medidas apropriadas para prover o acesso de pessoas com deficiência ao apoio que necessitarem no exercício de sua capacidade legal. 4. Os Estados Partes assegurarão que todas as medidas relativas ao exercício da capacidade legal incluam salvaguardas apropriadas e efetivas para prevenir abusos, em conformidade com o direito internacional dos direitos humanos. Essas salvaguardas assegurarão que as medidas relativas ao exercício da capacidade legal respeitem os direitos, a vontade e as preferências da pessoa, sejam isentas de conflito de interesses e de influência indevida, sejam proporcionais e apropriadas às circunstâncias da pessoa, se apliquem pelo período mais curto possível e sejam submetidas à revisão regular por uma autoridade ou órgão judiciário competente, independente e imparcial. As salvaguardas serão proporcionais ao grau em que tais medidas afetarem os direitos e interesses da pessoa. 5. Os Estados Partes, sujeitos ao disposto neste Artigo, tomarão todas as medidas apropriadas e efetivas para assegurar às pessoas com deficiência o igual direito de possuir ou herdar bens, de controlar as próprias finanças e de ter igual acesso a empréstimos bancários, hipotecas e outras formas de crédito financeiro, e assegurarão que as pessoas com deficiência não sejam arbitrariamente destituídas de seus bens". Grifos adicionados.

Nesse sentido, determina o art. 85 do EPD que a curatela "afetará tão somente os atos relacionados aos direitos de natureza patrimonial e negocial", não alcançando o direito ao próprio corpo, à sexualidade, ao matrimônio, à privacidade, à educação, à saúde, ao trabalho e ao voto.

"Além disso, os tradicionais processos de interdição não permitiam a análise pormenorizada das vicissitudes circundantes à história de cada pessoa. Observava-se a deficiência enquanto patologia e não o sujeito, a pessoa de carne cujos interesses estavam em discussão. Desconsiderava-se que, independentemente do diagnóstico, o conjunto de fatores pessoais e de experiências externas poderia interferir substancialmente para o modo como a pessoa responderia às suas limitações psíquicas e/ou intelectuais" (MENEZES, 2016, p. 34).

Na Roma e na Grécia antigas, o pai podia enjeitar ou afogar as crianças malformadas (ARIĖS; DUBY, 2009, p. 21).

5 "O saber científico, em todas as suas expressões, encontrou na medicina um de seus principais instrumentos e tornou a vida humana objeto do saber teórico, especialmente do conhecimento biológico" (BARBOZA, 2013, p. 4).

6 "O Projeto Beviláqua usara a expressão 'alienados de qualquer espécie', mas o Código de 1916 preferiu adotar a denominação loucos de todo o gênero, tradicionalmente usada por nossos juristas de então. (...) quando o Código Civil de 1916 fazia referência à loucura, não se queria limitar àqueles casos de distúrbio mental que faziam do enfermo um furioso, mas aludia a toda espécie de desequilíbrio das funções cerebrais, sejam as que provinham de qualquer malformação congênita, sejam as que fossem subsequentes a uma enfermidade geral ou específica, sejam as que decorressem de um acidente e, no seu alcance, compreendiam toda enfermidade, vício ou lesão que afetasse o comportamento psíquico do indivíduo na sua vida de relação em sociedade" (PEREIRA, 2018, p. 232). 
O Código Civil de 2002 aboliu essa expressão, mas manteve no rol dos absolutamente incapazes os que, por enfermidade ou deficiência mental, não tivessem o necessário discernimento para a prática dos atos da vida civil (art. $\left.3^{\circ}, \mathrm{II}\right)$, considerando, ainda, a deficiência mental como causa de incapacidade relativa, capaz de reduzir o discernimento (art. $\left.4^{\circ}, \mathrm{II}\right)$.

A deficiência intelectual ou psíquica era, assim, causa de sujeição à curatela, por força do art. 1.767, III, do CC/02. Não obstante já se ressaltasse a imprescindibilidade de se definir os limites da curatela na sentença que a determinava mesmo antes do EPD, ${ }^{7}$ na prática, a interdição representava uma restrição absoluta de direitos para o curatelado, que englobava inclusive atos existenciais, desconsiderando a extensão da deficiência na delimitação dos atos para os quais a pessoa precisaria efetivamente de auxílio.

Sob o manto do viés protetivo, reproduzia-se, desse modo, uma visão excludente e discriminatória a respeito da pessoa com deficiência, o que motivou as alterações no texto legal. Nota-se, inicialmente, que a transformação do tratamento conferido à pessoa com deficiência intelectual ou psíquica foi um importante reflexo do movimento antimanicomial, iniciado nos anos 70 e consolidado com a promulgação da Lei n. ${ }^{0}$ 10.216/01, que dispõe sobre a proteção e os direitos das pessoas portadoras de transtornos mentais e redireciona 0 modelo assistencial em saúde mental (ALMEIDA, 2019, p. 80). Com o EPD, as pessoas com deficiência mental foram excluídas do rol dos arts. $3^{\circ}$ e $4^{\circ}$ do $\mathrm{CC} / 02$, tornando-se, desse modo, a princípio, plenamente capazes.

Buscou o EPD superar o modelo médico para implementar o modelo social de deficiência, ${ }^{8}$ já incorporado por força da Convenção, que considera a necessidade de se considerar fatores não apenas científicos, mas sobretudo sociais para se definir o tratamento jurídico direcionado à pessoa com deficiência. Em suma, devem-se buscar mecanismos para viabilizar a participação plena da pessoa com deficiência em sociedade, eliminando-se as barreiras nos sistemas de educação, no trabalho, nos meios de transporte, nas construções, nos meios de comunicação etc. ${ }^{9}$

Não obstante os inegáveis avanços em termos de inclusão das pessoas com deficiência, as alterações legislativas promovidas pelo EPD geraram alguns questionamentos, na medida em que, em algumas situações, poderiam gerar o efeito inverso ao pretendido pelo legislador, acarretando algum grau de desproteção das pessoas com deficiência.

Antes mesmo de entrar em vigor, já se discutia a possível derrogação de algumas disposições do EPD pelo Código de Processo Civil de 2015 - CPC/15, considerando que o CPC/15 foi publicado antes do EPD, mas entrou em vigor depois do EPD. Dúvidas surgiram em relação à legitimidade da própria pessoa para requerer sua curatela, já que o art. 1.768, que teve o inciso IV (que previa a autocuratela) incluído pelo EPD, foi revogado pelo $\mathrm{CPC} / 15 .^{10}$

\footnotetext{
Em 2013, o Enunciado 574, VI Jornada de Direito Civil do CJF, já previa que a decisão judicial de interdição deveria "fixar os limites da curatela para todas as pessoas a ela sujeitas, sem distinção, a fim de resguardar os direitos fundamentais e a dignidade do interdito".

"Nesse sentido, pondera-se que, muito embora os casos de incapacidade venham previstos em lei, em dispositivos de ordem pública, os tempos são de flexibilização da curatela, a qual passa a exigir uma interpretação compatível com os valores de que é portadora a pessoa humana na Constituição, como forma de assegurar que as exigências particulares de cada um sejam efetivamente respeitadas. Em lugar de apenas se adotar a substituição de uma pessoa concreta por outra, que não necessariamente estará apta a viabilizar os seus reais interesses, as aptidões do interditando deverão ser examinadas uma a uma. (...) Acredita-se que a diversidade de transtornos mentais permanentes e suscetíveis de afetar a capacidade da pessoa demanda um tipo de intervenção diferenciada, conforme o grau de transtorno mental existente. Os transtornos mentais recaem de forma diferenciada sobre o desenvolvimento dos cidadãos; assim, a curatela não pode consistir em uma solução rígida e absoluta, incompatível com a elasticidade inerente à personalidade humana. Considera-se, então, que a interdição ou não de um portador de transtorno mental deverá depender da verificação contextualizada da sua capacidade para a prática dos atos da vida civil” (ABREU; MANUEL, 2014, p. 116).

8 "O modelo social de direitos humanos considera que o tratamento jurídico devido às pessoas com deficiência (sejam elas capazes ou incapazes) não deve partir de um fundamento exclusivamente científico, porém, preponderantemente social. A deficiência é um fenômeno complexo que não se limita a um atributo médico e individual da pessoa. Há um contexto social que requer adaptação para que todo ser humano participe ativamente da vida comunitária e se mantenha como o centro das decisões que lhe afetem" (ROSENVALD, 2016, p. 750).

9 "Desde esta perspectiva, las personas con discapacidad son discapacitadas como consecuencia de la negación por parte de la sociedad de acomodar las necesidades individuales y colectivas dentro de la actividad general que supone la vida económica, social y cultural” (PALACIOS, 2008, p. 121).

10 "Cumpre lembrar que as Leis em questão são de igual hierarquia, razão pela qual o CPC derrogará o Estatuto da Pessoa com Deficiência e o Código Civil, inclusive naquilo que houver sido alterado pelo Estatuto, nos termos do art. $2^{\circ}$, $\S 1^{\circ}$, da Lei de Introdução às Normas do Direito Brasileiro. Ainda que se considere o Estatuto como lei especial, a derrogação de ambas as Leis (Estatuto e Código Civil) se mantém, mesmo em face do disposto no $\S 2^{\circ}$ do art. $2^{\circ}$, que apenas seria aplicável caso não houvesse a incompatibilidade acima referida, critério que deve prevalecer, vale dizer: os dispositivos do Estatuto da Pessoa com Deficiência e do Código Civil que forem incompatíveis com o CPC estarão derrogados. É indispensável ressaltar, diante de eventual dúvida quanto à vigência ou alcance de dispositivos legais, que em nenhum momento as pessoas com deficiência ficarão ao desamparo, na medida em que estarão resguardadas diretamente pela Constituição da República de 1988 e pela Convenção de 2008" (BARBOZA; ALMEIDA, 2016, p. 134/135).
} 
Não obstante o descompasso legislativo, não se deve entender pela impossibilidade da autocuratela. ${ }^{11}$ Isso ocorre porque, ainda que essa disposição não esteja expressamente prevista na legislação infraconstitucional, a legitimidade da própria pessoa requerer a sua curatela decorre da própria Convenção, que tem como viés a promoção da autonomia e liberdade de a pessoa com deficiência fazer as próprias escolhas, como já apontado. Como a Convenção possui força constitucional, tendo sido aprovada pelo quórum qualificado do art. $5^{\circ}$, parágrafo $3^{\circ}$, da $\mathrm{CF} / 88$, a legislação infraconstitucional deve ser lida sob essa perspectiva, sob pena de se contrariar a Carta Magna. ${ }^{12}$

Atenta-se, ainda, para fato de a ação de interdição ter sido prevista pelo $\mathrm{CPC} / 15$, sendo revogadas as disposições processuais do Código Civil. Contudo também a legislação processual busca incorporar a visão mais atual a respeito da pessoa com deficiência, o que pode ser verificado, por exemplo, com a substituição da lógica de "interrogatório" pela "entrevista pessoal", que, ao lado da perícia realizada por equipe multidisciplinar, são etapas necessárias para se definir os limites e a extensão da curatela. ${ }^{13}$

Outro ponto que vem sendo objeto de questionamento diz respeito à possibilidade de a restrição da extensão da curatela a atos negociais ou patrimoniais gerar, em algumas situações, como efeito inverso, a desproteção da pessoa com deficiência. Isso ocorre porque há casos em que a pessoa não possui qualquer possibilidade de agir ou de se manifestar ou não se apresenta condições de atuar de forma autônoma sem atingir a si próprio ou a seu patrimônio, necessitando da atuação do curador. Heloisa Helena Barboza chama atenção, ainda, para as hipóteses em que o exercício de direitos se torna exageradamente incômodo ou requer sacrifício e/ou sofrimento evitável para a pessoa com deficiência (BARBOZA, 2016, p. 91).

Em tais situações, por outro lado, a ausência de intervenção do curador iria de encontro ao melhor interesse do curatelado, devendo-se, portanto, admitir excepcionalmente a extensão da curatela a atos existenciais, em circunstâncias muito especiais, que justifiquem essa contrariedade ao Estatuto, em nome da preservação da própria pessoa com deficiência. ${ }^{14}$ Alguns tribunais estaduais já vêm entendendo nesse

1 Alguns juristas preferem a nomenclatura autointerdição, que, além de ser mais técnica, evita confusão com o instituto da autocuratela (instrumento em que a pessoa faz escolhas para o futuro, caso venha a se tornar incapaz): "O art. 1.768 do Código Civil foi revogado, pois o regramento da legitimidade para a propositura da ação interdição passou a estar no art. 747 do CPC. Agora, a Lei n. 13.146/2015, ignorando a revogação do dispositivo pelo CPC, acrescenta-lhe um inciso (art. 1.768, IV, Código Civil), para permitir a promoção da interdição pelo próprio interditando legitimando a autointerdição, portanto. Não há essa previsão no art. 747, CPC. O artigo alterado será revogado a partir de 18 de março de 2016. O que, então, fazer? Parece que a melhor solução é considerar que a revogação promovida pelo CPC levou em consideração a redação da época, em que não aparecia a possibilidade de autointerdição. A Lei n. 13.146/2015 claramente quis instituir essa nova hipótese de legitimação, até então não prevista no ordenamento - e, por isso, não pode ser considerada como "revogada" pelo CPC. O CPC não poderia revogar o que não estava previsto. Assim, será preciso considerar que há um novo inciso ao rol do art. 747 do CPC, que permite a promoção da interdição pela 'própria pessoa"'. (DIDIER, 2015).

12 "A derrogação expressa do art. 1.768 pelo Código de Processo Civil a entrar em vigor em março de 2016 não deve significar a extinção da possibilidade de requerimento da curatela pelo interessado. Considerados os princípios da Convenção, que tem natureza de norma constitucional, e o que mais consta do Estatuto da Pessoa com Deficiência, subtrair da pessoa com deficiência a legitimidade para requerer sua própria curatela seria negar sua própria capacidade, ignorar sua autonomia, vale dizer em última análise, violar o principal objetivo da Convenção, que tem força de norma constitucional, e da Lei" (BARBOZA, 2015, p. 451).

13 Nesse sentido: "Apelação cível. Interdição. Sentença de procedência. Insurgência do Ministério Público. Apontada nulidade no procedimento. Entrevista do interditando e perícia médica não realizadas. Imprescindibilidade. Medidas necessárias à constatação segura acerca da incapacidade e sua extensão. Inteligência dos arts. 751 e 753, ambos do CPC/2015. Mácula existente. Decisum baseado apenas na constatação do oficial de justiça por ocasião da tentativa de citação, que atestou ter dúvidas da capacidade do interditando e atestados médicos particulares que não especificaram a extensão das anomalias. Fragilidade do contexto probatório. Melhor dilação probatória que se impõe. Sentença cassada. Retorno dos autos à origem para o regular processamento do feito. Recurso conhecido e provido". TJSC, $6^{a}$ Câmara de Direito Civil, Apelação Cível n. ${ }^{\circ}$ 0304589-61.2015.8.24.0011, Rel. Des. André Luiz Dacol, julg. 06.06.2017.

14 "Em verdade, o dispositivo procura evitar a coisificação da pessoa curatelada que não pode ter a sua integridade fisiopsíquica comprometida pela atuação indevida do curador. Porém, e se o curatelado não tiver qualquer capacidade de agir, estiver sob tratamento médico, houver a necessidade de se decidir sobre certa intervenção em matéria de saúde e não existir familiar em condições de fazê-lo? Haveria sim a possibilidade de intervenção do curador, mas sempre com a intenção de realizar o interesse fundamental do curatelado, assim entendido como as suas preferências genuínas, sua percepção do mundo, suas convicções pessoais acerca da própria identidade" (MENEZES, 2015).

Também nesse sentido: "É de se ressaltar ainda que, nos termos do art. $4^{\circ}$, III, do Código Civil, é considerada relativamente incapaz a pessoa que não possa exprimir sua vontade, temporária ou permanentemente, de forma consciente e autônoma, relativa a determinados atos patrimoniais/ negociais, mas que, eventualmente, podem atingir os existenciais, desde que como salvaguarda para prevenir abusos e impedir que direitos sejam frustrados" (BARBOZA; ALMEIDA JÚNIOR, 2016, p. 219/220).

"Nada impede que seja preciso que os limites da curatela se circunscrevam ao cuidado com questões extrapatrimoniais ou toquem simultaneamente situações existenciais e patrimoniais" (ABREU, 2016, p. 560). 
sentido, ampliando os efeitos da curatela, sobretudo para tratamentos de saúde, intervenções cirúrgicas, internações, exercício da guarda da prole, entre outros. ${ }^{15}$

Assim, a determinação legal de que a curatela deve se limitar a atos de natureza negocial ou patrimonial não pode gerar uma espécie de engessamento ao revés em prejuízo da pessoa com deficiência quando a situação concreta demandar uma intervenção do curador para se preservar justamente o que o legislador pretendeu resguardar quando fez a restrição - obviamente, em determinadas circunstâncias. É preciso superar a restrição excessiva que era estabelecida com a interdição nos moldes anteriores, mas sem ignorar as realidades que demandam soluções diversas da proposta no texto legal. ${ }^{16}$

Também é necessário atentar para alguns desafios relativos à implementação do EPD, na medida em que de nada adianta alterar o texto da lei sem que haja uma mudança de tratamento na prática das questões que envolvem pessoa com deficiência, sob pena de se recair em uma situação de inefetividade. ${ }^{17}$ A indicação precisa dos atos alcançados pela curatela na sentença é imprescindível para que a curatela se opere de fato "sob medida". ${ }^{18}$

Somado a todas essas questões, o advento do EPD gerou muitas dúvidas e discussões ao promover alterações significativas no regime das incapacidades, na medida em que a definição da capacidade legal gera reflexos em todo o ordenamento jurídico, mormente no sistema das invalidades. Por sua especial relevância, o tema será tratado de forma destacada, na sequência.

\section{Os reflexos das alterações do EPD sobre o regime das invalidades dos atos praticados por pessoas deficiência intelectual ou psíquica}

Como um dos mais significativos reflexos das modificações implementadas pelo EPD, destaca-se o impacto das alterações promovidas nos arts. $3^{\circ}$ e $4^{\circ}$ do Código Civil sobre o regime das invalidades, tradicionalmente estanque, absoluto e baseado em relações de caráter patrimonial, mas que, contudo, acabava por gerar restrições atinentes ao campo existencial da pessoa considerada incapaz.

Embora dotadas de personalidade - definida por Clóvis Beviláqua como a aptidão genérica para adquirir direitos e contrair deveres na ordem jurídica ${ }^{19}$-, às pessoas com deficiência era restringida a capacidade de fato, considerada a aptidão para utilizar e exercer os direitos e obrigações por si mesmo (PEREIRA, 2018, p. 221). Nesse sentido, importa observar que, tradicionalmente, enquanto a capacidade de direito

5 Nesse sentido, já decidiu a $5^{\mathrm{a}}$ Turma Cível do TJDF: "Uma vez que a perícia conclua que o interditado está em estado de "comprometimento do pensamento, do afeto, do juízo de realidade, da memória recente e tardia, da atenção, da concentração e do pragmatismo", é necessária a ampliação dos efeitos da curatela para, além do encargo à prática de atos de natureza patrimonial e negocial, a curadora nomeada também fique responsável por orientar e acompanhar o interditado em seu tratamento médico, além de prover a sua saúde, de acordo com as necessidades do

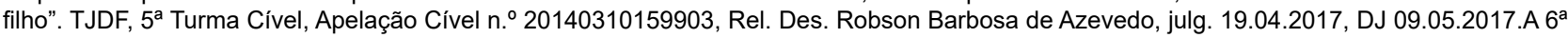
Câmara Cível do TJRJ já fixou, também, a curatela para atos existenciais, nos seguintes termos: "Limites: a curadora deve auxiliá-la nos cuidados básicos de sua pessoa, podendo morar sozinha, sendo que a administração dos bens ao cargo da curadora, não podendo exercer a guarda de sua prole, apta ao trabalho, desde que supervisionada. Igualmente, cabe a Curadora administrar a pessoa da Apelante, inclusive que decisões sobre sua saúde, tratamento, intervenções cirúrgicas, internações, entre outras. Poderá exercer atividade laborativa supervisionada e que não demande muita responsabilidade". TJRJ, 6ª C.C., Apelação Cível n. ${ }^{\circ}$ 0001090-18.2014.8.19.0044, Rel. Des. Teresa de Andrade Castro Neves, julg. 07.06.2017.

Ver, ainda: TJMG, $7^{a}$ C.C., Apelação Cível n. ${ }^{0}$ 1.0245.13.011494-6/001, Rel. Des. Alice Birchal, julg. 14.02.2017, DJ 21.02.2017; TJRS, 8ª C.C., Apelação Cível n. ${ }^{\circ} 70069713683$, Rel. Des. Rui Portanova, julg. 15.09.2016, DJ 19.09.2016; TJSP, 5a Câmara de Direito Privado, Apelação Cível n. ${ }^{\circ}$ 0001611-45.2013.8.26.0547, Rel. Des. James Siano, julg. 13.03.2016, DJ 13.03.2016.

16 "Dito isto, a fixação dos limites da curatela deve evitar dois extremos: de um lado, a proteção excessiva que aniquila toda autonomia da pessoa, lançando-a em um estado semelhante ao da morte civil. De outro lado, a limitação da curatela apenas à administração do patrimônio, excluindo, em abstrato e a priori, eventual e necessária proteção no plano das questões existenciais. Se houver necessidade de proteger o interdito no âmbito dessas questões não patrimoniais, a curatela deverá recair também sobre tais interesses, respeitadas as salvaguardas importantes à efetivação dos direitos humanos" (MENEZES, 2015).

17 "Muito esforço será exigido do intérprete e do aplicador do direito, para que se dê efetividade ao que se encontra expresso no Estatuto da Pessoa com Deficiência, mas principalmente para que se evitem duas atitudes de todo prejudiciais tais como: (i) a interpretação a partir da doutrina tradicional sobre o assunto, construída à luz de outro paradigma; (ii) a permanência no âmbito da retórica, situação infelizmente tão comum quando se trata de questões atinentes a pessoas vulneráveis" (BARBOZA; ALMEIDA, 2016, p. 133).

18 Expressão utilizada por Célia Barbosa Abreu (ABREU, 2016).

19 "Não depende esta da consciência ou da vontade do indivíduo. A criança, mesmo recém-nascida, o deficiente mental ou o portador de enfermidade que desliga o indivíduo do ambiente físico ou moral, não obstante a ausência de conhecimento da realidade, ou a falta de reação psíquica, é uma pessoa, e por isso mesmo dotado de personalidade, atributo inseparável do ser humano dentro da ordem jurídica, qualidade que não decorre do preenchimento de qualquer requisito psíquico" (PEREIRA, 2018, p. 181/182). 
ou de gozo era reconhecida a todo ser humano, decorrendo da personalidade, a capacidade de fato ou de exercício constituiria a possibilidade de praticar atos civis de forma autônoma, havendo no ordenamento jurídico pré-EPD uma espécie de presunção legislativa de que as pessoas com deficiência intelectual ou psíquica estariam despidas desta última.

Contudo deve-se observar que a dissociação entre titularidade e exercício, que permeia a diferenciação entre capacidade de direito e capacidade de fato, apesar de se amoldar à estrutura dos direitos subjetivos patrimoniais, não se revela possível nas situações existenciais (TEPEDINO; OLIVA, 2016, p. 237), indissociáveis da pessoa humana.

Não obstante, na prática, a incapacidade de fato se tornou uma barreira para o exercício da autonomia das pessoas com deficiência intelectual ou psíquica, principalmente diante da observação de que a capacidade civil acabou servindo como critério para atribuição da titularidade de direitos fundamentais, ${ }^{20}$ não havendo uma efetiva avaliação em concreto das limitações de cada pessoa individualmente. Essa realidade prática foi um dos fatores que motivou as alterações no texto da lei, aliado às transformações decorrentes do movimento antimanicomial e das frentes de não discriminação e inclusão das pessoas com deficiência.

Com o advento do EPD, foram excluídos do rol dos absolutamente incapazes (art. $3^{\circ}, \mathrm{CC} / 02$ ) aqueles que "por enfermidade ou deficiência mental" não tivessem o necessário discernimento para a prática desses atos e os que, mesmo por causa transitória, não pudessem exprimir sua vontade. Manteve o legislador, assim, apenas os menores de dezesseis anos como absolutamente incapazes.

No rol dos relativamente incapazes (art. $\left.4^{\circ}, \mathrm{CC} / 02\right)$ foram excluídos aqueles que "por deficiência mental" tivessem o discernimento reduzido e os "excepcionais, sem desenvolvimento mental completo", mantendo-se os maiores de dezesseis e menores de dezoito anos, os ébrios habituais e os viciados em tóxico e os pródigos, e acrescentando os que, "por causa transitória ou permanente, não puderem exprimir sua vontade", anteriormente considerados absolutamente incapazes.

Nota-se que, apesar de representar, por um lado, a tentativa de excluir do ordenamento jurídico o tratamento abstrato e discriminatório tradicionalmente estabelecido pelo legislador em relação à pessoa com deficiência intelectual ou psíquica, a reconfiguração do sistema de capacidades gerou impactos significativos sobre todo o ordenamento, não passando incólume a críticas.

Uma das principais questões que devem ser pontuadas refere-se ao fato de o EPD tratar do mesmo modo todas as formas de deficiência, sem estabelecer diferenças entre a deficiência física e a deficiência intelectual ou psíquica. Em outras palavras, deixou o legislador de reconhecer as peculiaridades de cada deficiência, que demandam regimes de proteção diferenciados, tratando "de forma igual os desiguais". ${ }^{21}$

Essa primeira observação vai permear outras dificuldades, na medida em que a exclusão das pessoas com deficiência mental dos arts. $3^{\circ}$ e $4^{\circ}$ pode gerar, em alguns casos, a desproteção desses grupos vulneráveis. Ao se considerar a pessoa com deficiência plenamente capaz, a princípio: (i) os atos praticados por elas passam a ser plenamente válidos, não incidindo os arts. 166, I, e 171, I, do CC/02; (ii) os prazos prescricionais e decadenciais passam a correr contra ela, afastando-se os arts. 198, I, e 208 do CC/02; (iii) a quitação por ela dada passa a ser válida e eficaz, não sendo aplicável o art. 310 do CC/02; (iv) ela passará a responder com seus próprios bens pelos danos provocados, e não mais de forma subsidiária, já que não seria aplicável o art. 928 do CC/02 (SIMÃO, 2015).

\footnotetext{
20 "Direito humanos, direitos fundamentais e direitos da personalidade se entrelaçaram para viabilizar uma tutela geral da pessoa nas relações públicas e privadas, considerando-se que nessas últimas também se verificam lesões à dignidade e aos direitos mais emitentes do sujeito. Exemplificativamente, as pessoas com deficiência psíquica e intelectual foram, por muito tempo, excluídas de uma maior participação na vida civil, tiveram sua capacidade jurídica mitigada ou negada, a sua personalidade desrespeitada, seus bens espoliados, a sua vontade e sua autonomia desconsideradas. Ao cabo e ao fim, a capacidade civil serviu de critério para atribuir titularidade aos direitos fundamentais" (MENEZES, 2015, p. 3).

21 "Ao tratar a deficiência de modo amplo e geral, a lei brasileira não deu respostas mais concretas a determinadas deficiências que exigiriam um tratamento mais específico, levando em conta que as barreiras são mais ou menos problemáticas dependendo da natureza do impedimento (físico, mental, intelectual ou sensorial). Ao trazer previsões mais genéricas, o EPD tratou todos os deficientes de forma semelhante, não dando atenção às peculiaridades de cada impedimento, resultando em um tratamento igual aos desiguais" (LIMA; VIEIRA; SILVA, 2017, p. 25).
} 
Além disso, houve a supressão da gradação legal entre incapacidade absoluta e relativa para as pessoas com deficiência, na medida em que o legislador restringiu os absolutamente incapazes aos menores de 16 anos. Diante dessa situação, pode-se configurar uma situação anacrônica: a pessoa que não possui qualquer discernimento ou não consegue se comunicar (ex: pessoa em coma) seria considerada relativamente incapaz, enquanto o adolescente de 15 anos seria absolutamente incapaz. Esse contrassenso revela como o modelo abstrato apresenta falhas relevantes, o que vem motivando um trabalho de construção doutrinária para reformular o regime de incapacidades e também os outros institutos afetados pelo novo contexto normativo.

No caso do risco de curso da prescrição pela exclusão da pessoa com deficiência como incapaz, a título de exemplo, sustentam Micaela Fernandes e Marcos Gonçalves que, sendo a consciência e o discernimento os elementos nucleares que permitem o início da fluência dos prazos prescricionais, tais fatores devem ser também considerados na modulação dos efeitos da fluência dos prazos prescricionais. Assim, havendo limitação em relação ao agir, também deve ser limitada a fluência da prescrição. ${ }^{22}$

Eduardo Nunes de Souza e Rodrigo da Guia também entendem pela possibilidade de modulação da prescrição de acordo com a presença ou ausência de discernimento do agente diante da situação fática concretamente analisada. Desse modo, o marco temporal para a suspensão ou a interrupção da prescrição será a constatação da situação de vulnerabilidade que impede ou dificulta a ação do agente..$^{23}$

Em relação à teoria das invalidades, deve-se lembrar de que um dos requisitos de validade do negócio jurídico é a existência de agente capaz (art. 104, I, CC/02), sendo nulo o negócio quando celebrado por pessoa absolutamente incapaz (art. 166, I, CC/02), e anulável quando celebrado por pessoa relativamente incapaz (art. 171, I, CC/02). Pela ótica tradicional das invalidades, sendo a pessoa com deficiência considerada plenamente capaz, os atos praticados por ela seriam considerados, portanto, válidos caso não incidisse outra causa de invalidade.

Desse modo, questiona-se se a não incidência da causa de invalidade poderia gerar a desproteção da pessoa com deficiência, na medida em que seriam mantidos, a princípio, os efeitos de eventuais negócios prejudiciais à parte mais vulnerável, acarretando uma situação menos benéfica justamente para aquele que o EPD buscou tutelar.

Diante da necessidade de enfrentamento de tais questões, o próximo tópico terá como escopo apresentar propostas com o fito de tentar compatibilizar as modificações promovidas pelo EPD, que busca conferir maior autonomia às pessoas com deficiência, com o aspecto protetivo atrelado à determinação da capacidade civil e às invalidades.

\section{Propostas para a compatibilização da exclusão das pessoas com deficiência intelectual ou psíquica dos arts. $3^{\circ}$ e $4^{\circ}$ do $\mathrm{CC} / 02$ com as finalidades do EPD}

As alterações promovidas pelo EPD refletem a necessidade de se considerar o sujeito de direito concretamente, tendo em vista que a adoção do modelo abstrato e geral, sob o manto da ideia de "proteção"

\footnotetext{
22 "Sendo certo que o elemento nuclear que permite o início da fluência dos prazos prescricionais é a consciência e discernimento dos efeitos do ato ou da omissão, a garantia de capacidade, que é tributada a todas as pessoas com deficiência psíquica ou intelectual, não é suficiente para atestar tal discernimento, razão pela qual devem igualmente ser modulados os efeitos da fluência dos prazos prescricionais. Admitido, no âmbito funcional do EPD, que a tutela da pessoa com deficiência abrange comportamento positivo e negativo - do Estado e dos particulares - que permitam a inclusão e autonomia do deficiente, impondo a interferência mínima, porém eficiente para garantir tal função, é de se concluir que eventual limitação no agir implica em limitar, igualmente, a fluência da prescrição" (FERNANDES; GONÇALVES, 2019, p. 51).

23 "Assim, ainda que o legislador alegadamente tenha pretendido excluir as pessoas com deficiência psíquica ou intelectual do âmbito de abrangência do regime legal das incapacidades, faz-se necessário reconhecer-lhes a proteção do óbice à prescrição desde a constatação da ausência de discernimento. À semelhança do que se propõe para a generalidade das hipóteses de discernimento comprometido ou impossibilidade de exercer a pretensão, deve-se reconhecer que, após o advento do Estatuto da Pessoa com Deficiência, o marco temporal para impedimento ou suspensão do prazo prescricional coincide com o início da situação fática de vulnerabilidade, tal como aludida, relegando-se à eventual decisão judicial fixadora de curatela mero caráter de facilitação probatória" (SOUZA; SILVA, 2017, p. 148).
} 
do incapaz, acabou por acarretar a exclusão de vulneráveis na prática, não considerando as efetivas limitações existentes em cada um e as possibilidades de exercício de sua autonomia. ${ }^{24}$

Indaga-se, nesse contexto, qual deverá ser o elemento determinante para que se verifique, em concreto, a existência ou não da possibilidade de praticar, por si só, os atos da vida civil, ${ }^{25}$ a fim de se realizar o controle valorativo dos atos de autonomia realizados pelas pessoas com deficiência intelectual ou psíquica.

Sob esse aspecto, é importante observar que, antes do advento do EPD, o critério do discernimento como definidor de capacidade civil era objeto de críticas por parte da doutrina. ${ }^{26}$ Contudo, sob a normativa anterior, o que se buscava superar era a presunção de ausência de discernimento das pessoas com deficiência intelectual ou psíquica, que acabou por ser estabelecida pelo legislador nos arts. $3^{\circ}$ e $4^{\circ}$, acarretando uma restrição tanto em relação aos atos de natureza patrimonial quanto aos atos existenciais.

Relembra-se que o art. $3^{\circ}$, inciso II do CC/02, em sua redação original, previa como absolutamente incapazes os que, por enfermidade ou deficiência mental, não tivessem o necessário discernimento para a prática dos atos da vida civil. $\mathrm{O}$ art. $4^{\circ}$, inciso II também incorporava essa lógica ao determinar que os que, por deficiência mental, tivessem o discernimento reduzido seriam considerados relativamente incapazes. Pela própria redação dos dispositivos, pode-se verificar que a ausência ou redução do discernimento era considerada um elemento decorrente da deficiência, e não efetivamente um fator autônomo a ser avaliado.

Com a exclusão dessa previsão, a utilização do discernimento como critério valorativo parece assumir novos contornos, na medida em que representa uma análise funcional e concreta, e não mais estrutural e abstrata, da possibilidade de a pessoa pensar e agir de forma consciente em determinadas circunstâncias. ${ }^{27}$ Em outras palavras: para que se avalie a validade ou não de um ato praticado por uma pessoa com deficiência intelectual ou psíquica, deve-se verificar se ela tinha ou não possibilidade de exteriorizar a sua vontade para a prática daquele ato naquele momento específico, com o exame das circunstâncias de cada situação. ${ }^{28}$ Cabe observar, contudo, que o reconhecimento da ausência de discernimento por parte da pessoa com deficiência não confere poderes de representação - tal qual delineados na perspectiva anterior ao EPD ao curador, na medida em que a representação depende de prévia determinação legal. ${ }^{29}$ Esses conceitos, portanto, precisam ser redesenhados à luz Convenção e do EPD, a fim de cumprir a verdadeira função da tutela promocional da pessoa com deficiência.

24 "Ao modelo abstrato contrapôs-se, com especial força nas últimas décadas, a realidade concreta: em numerosas hipóteses, os incapazes acabam tolhidos de uma parcela de autonomia que se sentem em condições de exercer livremente. O regime abstrato e geral de "proteção" ao incapaz acaba se convertendo em instrumento de uma abordagem excludente, como se vê no exemplo historicamente recente da mulher casada. A designação de certa pessoa como "incapaz" - expressão que, por si só, já é carregada de significado negativo - assume, não raro, caráter discriminatório, como se vê com alguma frequência em casos envolvendo silvícolas, pródigos ou ébrios naturais" (NEVARES; SCHREIBER, 2016, p. 42).

25 Rose Meireles caracteriza a autonomia privada como "auto-regulamentação de interesses, patrimoniais e não-patrimoniais. Trata-se de um princípio que confere juridicidade àquilo que for definido pelo titular para o regramento de seus interesses, por meio das vicissitudes jurídicas relacionadas às situações subjetivas respectivas" (MEIRELES, 2009, p. 74).

26 "O critério do discernimento é essencial para situações patrimoniais, porém não é decisivo quando se trata de um valor indisponível como a personalidade humana. Não é plausível aceitar que, baseado apenas na saúde mental de uma pessoa, se pretenda intervir em seus direitos fundamentais, nas suas liberdades individuais, privacidade, intimidade, honra, imagem, entre tantos aspectos da sua personalidade" (ABREU, 2007, p. 13).

27 "Como uma pessoa inconsciente, que sobrevive em estado vegetativo, poderá agir na sua nova condição de relativamente incapaz? Se ela não se comunica de modo algum, como saber qual é a sua intenção e como ela praticará um ato formal? O EPCD não oferece resposta a essas circunstâncias, o que poderá redundar em desproteção. O ponto fulcral para a revisão do regime das incapacidades não deveria ser a existência ou não de deficiência, mas sim a presença de discernimento e da capacidade de comunicação" (LAGO JÚNIOR; BARBOSA, 2017, p. 11).

28 "No ponto, exsurge um ponto de interseção entre a teoria das incapacidades e as pessoas com deficiência física ou psíquica. Isso porque uma pessoa com deficiência, eventualmente, por algum fator pessoal, pode estar impossibilitada de manifestar a sua vontade, temporária ou definitivamente. Seria o caso de uma pessoa privada totalmente de discernimento mental. É certo que determinadas doenças ou estados psicológicos do organismo humano reduzem a capacidade de compreensão da vida e do cotidiano, impossibilitando a manifestação de vontade. Daí a opção legislativa de reconhecer tais pessoas como incapazes relativamente. Advirta-se por oportuno: a causa incapacitante, nessa hipótese, não reside na patologia ou no estado psíquico, mas na impossibilidade de exteriorizar a vontade" (FARIAS; ROSENVALD, 2016, p. 917).

29 "A considerar que a representação legal depende de prévia determinação na lei e que as pessoas com deficiência psíquica e/ou intelectual foram retiradas do rol dos absolutamente incapazes, assinalado no art. $3^{\circ}$ do Código Civil, a curatela não poderia assumir poderes de representação. Mas importa destacar que o Estatuto da Pessoa com Deficiência previu a possibilidade de delinear uma curatela aberta à demanda do curatelando, inclusive, para atender às necessidades daquela pessoa absolutamente faltosa de juízo crítico e autonomia. Assim, é possível que nos autos do processo, o juiz reconheça a necessidade de confiar ao curador mais amplos poderes (art. $84, \S 3^{\circ}$ ) - fixando os limites da curatela na proporção das necessidades e das circunstâncias do caso sob exame. Por uma questão formal, no entanto, esses poderes não serão nominados como representação legal" (MENEZES, 2015, p. 21/22). 
Como observa Vitor Almeida, deve-se apartar, de certa forma, os conceitos de capacidade civil e autonomia privada, considerando-se que a autodeterminação, sobretudo no que diz respeito a atos existenciais, decorre da dignidade da pessoa humana, e não da capacidade civil. Nesse sentido, seria possível restringir a capacidade civil, mas não a autonomia, devendo-se auferir o discernimento no caso concreto, de modo a se restringir a autonomia apenas nas situações em que isso for necessário para tutelar a dignidade da própria pessoa (ALMEIDA, 2019, p. 159).

Nesse contexto, pode-se até cogitar na permanência da possibilidade de a pessoa com deficiência mental ser considerada relativamente ou absolutamente incapaz, a depender do quanto a enfermidade compromete a prática dos atos da vida civil, de acordo com a análise detida de cada caso concreto (LAGO JÚNIOR; BARBOSA, 2017, p. 12). Busca-se, assim, limitar as restrições à autonomia da pessoa com deficiência apenas às hipóteses concretamente necessárias, o que também vai permear a determinação das invalidades.

Além disso, não se pode esquecer que o EPD previu outras formas de apoio à pessoa com deficiência, buscando viabilizar a prática dos atos da vida civil, como a tomada de decisão apoiada, prevista no art. 1.783-A do Código Civil. ${ }^{30}$ Não obstante os questionamentos em relação à utilidade prática do instituto, fato é que a tendência passa a ser a de conferir instrumentos para o exercício da sua autonomia, preservando a sua capacidade civil.

Em relação à teoria das invalidades, Eduardo Nunes de Souza aponta que estas, embora estivessem tradicionalmente atreladas ao perfil estrutural do ato, possuindo natureza estática, adquirem, hoje, um papel funcional, devendo ser analisadas de forma dinâmica. Desse modo, embora a classificação dos atos inválidos como nulos ou anuláveis seja relevante para o intérprete, "a disciplina legalmente prevista para tais categorias deve ser apenas o início do trajeto a ser percorrido pelo julgador, a quem incumbe interpretálas e aplicá-las na unidade sistemático-teleológica do ordenamento" (SOUZA, 2017b). Em outras palavras: deve-se realizar uma análise dinâmica do ato, por meio de uma valoração concreta de seus efeitos, de modo que o interesse identificado em cada caso concreto determine o remédio adequado para cada causa de invalidade. ${ }^{31}$

Assim, por meio de uma perspectiva dinâmica e funcional das invalidades, avalia-se o grau de vulnerabilidade e discernimento em concreto da pessoa com deficiência intelectual ou psíquica para que se determine a nulidade ou anulabilidade do ajuste negocial, ${ }^{32}$ de modo que "a causa de invalidade em decorrência de um vício no ato (neste caso, a incapacidade) consiste apenas em um indicador de análise valorativa prévia, feita pelo legislador sobre os potenciais efeitos do ato" (SOUZA; SILVA, 2016).

Importa observar, ainda, que a noção de legalidade vem sendo modificada, indicando cada vez mais a noção de merecimento de tutela, ${ }^{33}$ que se configura como controle de cunho promocional, responsável por compatibilizar exercícios que, embora, em princípio, lícitos e não abusivos, possam eventualmente

30 Ana Luiza Nevares e Anderson Schreiber ressaltam, contudo, alguns contrassensos da tomada de decisão apoiada, como a excessiva burocratização, na medida em que há a necessidade de o procedimento para sua determinação se operar pelo meio judicial e de haver a intervenção do Ministério Público, o que faz com que o instituto possa ter pouca relevância prática (NEVARES; SCHREIBER, 2016, p. 52).

31 Como observa Eduardo Nunes de Souza, "não é a consequência jurídica (o grau de invalidade) que indica a relevância do interesse tutelado, mas o exato oposto: deve ser o interesse identificado em cada caso concreto a determinar o remédio adequado para a causa de invalidade" (SOUZA, 2017b).

32 "Apesar da excepcionalidade da medida protetiva, é preciso proteger as pessoas com deficiência mental ou intelectual também no âmbito do regime das invalidades dos negócios jurídicos, utilizando-se, para tanto, de uma perspectiva dinâmica e funcional que permita a valoração do real discernimento da pessoa com deficiência no momento da formação e em relação aos seus efeitos, de modo a ensejar a nulidade ou anulabilidade do ajuste negocial de acordo com o seu grau de vulnerabilidade e discernimento avaliado concretamente, buscando como norte a efetiva proteção da pessoa humana, que, independentemente da prévia moldura legal abstrata, é exigida pela Constituição da República" (BARBOZA; ALMEIDA JUNIOR, 2016, p. 226).

33 "Por outro lado, um aspecto (este sim) drasticamente modificado com a progressiva constitucionalização do direito civil foi a própria noção de legalidade, cada vez mais voltada à ideia de merecimento de tutela. Em um cenário de pluralidade de fontes normativas e crescente complexificação social, constata-se a insuficiência da função repressiva do direito para a solução de conflitos particulares. Nos casos, não mais tão raros, em que dois comportamentos privados, em princípio amparados pelo direito, entram em rota de colisão, impõe-se ao intérprete ponderar qual deles atende de modo mais satisfatório a uma função promocional, para conferir-lhe tutela prioritária. Esse juízo meritório se observa em todas as searas do direito civil: procura-se cada vez menos pelo culpado e cada vez mais pelo vulnerável; cada vez menos pela repressão, e cada vez mais pelo equilíbrio dos interesses; cada vez menos pela extinção dos atos desconformes e cada vez mais pelo equilíbrio dos interesses" (SOUZA; SILVA, 2017, p. 102/103) 
entrar em colisão (SOUZA, 2017a, p. 382). Na legalidade constitucional, o direito passa a ser um veículo de promoção de valores socialmente relevantes, incentivando e direcionado os comportamentos para atenderem aos valores do ordenamento. Assim, não basta que o ato seja conforme ao direito; ele deve ser também merecedor de tutela (SOUZA, 2017a, p. 45), não devendo o intérprete considerar fato e efeito como entidades incomunicáveis, sob pena de se afastar da realidade.

Nesse sentido, é possível que o intérprete module de forma diferenciada as consequências do reconhecimento da nulidade ou da anulação do ato, de acordo com a situação concretamente analisada, verificando se ele atende ou não aos valores do ordenamento, muito embora possa ser, em abstrato, considerado válido ou inválido. ${ }^{34}$

Sob a égide do sistema anterior ao EPD, o Tribunal de Justiça do Estado de São Paulo, por sua $3^{a}$ Câmara de Direito Privado, reconheceu a nulidade de contrato celebrado por pessoa com deficiência mental que não possuía o necessário discernimento para a prática dos atos de alienação imobiliária, ainda que não houvesse à época sentença de interdição. ${ }^{35}$ Considerou-se, desse modo, a situação concretamente apresentada, ainda que não houvesse determinação formal de curatela.

Para Eduardo Nunes de Souza e Rodrigo da Guia, a sentença que determina a curatela, ao prever os atos que serão objetos de restrição, estabelece uma espécie de presunção relativa de invalidade dos atos praticados sem a presença do curador, ${ }^{36}$ o que, por outro lado, não exclui a possibilidade de modulação dos efeitos da invalidade de acordo com as circunstâncias do caso concreto. Deve-se, nesse contexto, considerar não apenas as restrições da pessoa de forma isolada, mas também o meio externo, que pode ampliar ou agravar a limitação. ${ }^{37}$

Desse modo, conclui-se que, no âmbito do controle valorativo dos atos praticados por pessoas com deficiência intelectual ou psíquica, a análise do sujeito e da situação em concreto é imprescindível para se compatibilizar as alterações promovidas pelo EPD com o propósito protetivo do ordenamento e com as demais normas que regem a prática dos atos da vida civil. Em tais situações, cabe ao intérprete verificar o grau de vulnerabilidade e discernimento da pessoa para a prática daquele ato em específico no momento de exercitá-lo, a fim de modular os efeitos da invalidade ou não do ato de autonomia.

34 Na visão de Eduardo Nunes de Souza, "a aplicação da integralidade da ordem jurídica ao caso concreto autoriza o intérprete a modular de forma diferenciada as consequências do reconhecimento da nulidade ou da anulação do negócio, inclusive ao ponto de considerar certo ato em concreto funcionalmente válido, a despeito de conter uma causa de invalidade, por força do equilíbrio dos interesses por ele tangenciados. Do mesmo modo, mostra-se cabível cogitar da excepcional modulação de efeitos de determinado ato pela sentença que declare a sua validade plena, diante de interesses juridicamente relevantes" (SOUZA, 2017a, p. 386).

35 NEGÓCIO JURÍDICO. AÇÃO ANULATÓRIA. Realização de contrato por pessoa absolutamente incapaz, à data da celebração, ainda que por intermédio de imobiliária. Participação do representante, de forma tácita, não identificada. Negócio, na espécie, firmado anteriormente à vigência do Estatuto da Pessoa com Deficiência. Subsistência, àquela data, de deficiência mental capaz, por si só, de retirar do contratante o necessário discernimento para a prática dos atos de alienação imobiliária. Incidência do art. $3^{\circ}$, inc. II, do Código Civil, na redação original vigente à data do negócio. Irrelevância, ainda, de interdição decretada judicialmente poucos meses após a formalização da avença. Retardo mental identificado pela perícia técnica em momento anterior ao negócio. Depoimentos, ainda, que indicam a incapacitação desde a infância. Interdição prescindível ao reconhecimento de causa incapacitante. Decreto, na espécie, que estabelece a presunção legal de incapacidade de fato, não ilidindo a contemplação dessa circunstância por outros meios. Nulidade incontornável. Incidência do art. 166, inc. I, do Código Civil. APELO DESPROVIDO. TJSP, $3^{a}$ Câmara de Direito Privado, Apelação Cível n. ${ }^{\circ}$ 0006270-14.2012.8.26.0101, Rel. Des. Donegá Morandini, Comarca: Caçapava, publ. 13.10.2016.

36 "Uma vez fixada a curatela através de decisão judicial, a prática de ato de natureza patrimonial em desconformidade com a sentença acarretará sua nulidade, com fulcro no art. 166, VII, do Código Civil. Trata-se de aplicação do entendimento consagrado na doutrina e jurisprudência nacionais mesmo antes da reforma, no sentido de que a prática de ato por curatelado sem intervenção do curador padece de nulidade. De fato, traduziria efetivo contrassenso admitir a atuação individual da pessoa curatelada sem a intervenção do respectivo curador. Dessa constatação se pode depreender que a sentença instituidora de curatela implica, em matéria de invalidade negocial, presunção (relativa) de invalidade dos atos praticados sem a presença do curador, de modo semelhante ao que sucede com as causas legais gerais de invalidade dos atos. A relatividade dessa presunção decorre do fato de que o caso concreto pode apresentar valores idôneos a justificar a modulação dos efeitos da invalidade ou mesmo a afirmação da plena validade do ato, como se sustentou anteriormente" (SOUZA; SILVA, 2016, p. 26).

37 "Ademais, a despeito de um mesmo diagnóstico, as pessoas respondem aos desafios da vida de modo diferenciado, apresentando capacidades funcionais distintas, com uma maior ou menor independência. Disso resulta que a limitação funcional não deve ser apreciada de modo isolado com foco apenas na pessoa, sem uma referência ao meio externo, pois o background do meio pode ampliar aquela funcionalidade o agravá-la" (MENEZES, 2019, p. 76). 


\section{Considerações finais}

O Estatuto da Pessoa com Deficiência (EPD), Lei n. ${ }^{0} 13.146 / 2015$, ao promover alterações significativas no regime de capacidade civil, reacendeu um debate já travado pela doutrina relativo à insuficiência do modelo abstrato diante das diversas vicissitudes de cada situação analisada pelo intérprete e a necessidade de se promover uma releitura de institutos tradicionais do direito civil.

Com efeito, o modelo abstrato e estático de capacidade e invalidades revelou-se anacrônico frente à necessidade de se tutelar a dignidade humana diante de situações concretas, demandando do intérprete um olhar centrado não mais no comando geral da norma, mas sim na tábua axiológica constitucional, a partir dos valores tutelados pelo ordenamento em sua totalidade.

No caso das pessoas com deficiência intelectual ou psíquica, a superação desse modelo teve especial relevância, na medida em que restrição da capacidade civil e a determinação da curatela estabeleciam uma restrição quase absoluta de direitos, alcançando na prática inclusive atos existenciais, o que acabava por macular também o exercício de direitos fundamentais.

No entanto as modificações realizadas pelo EPD demandam uma releitura sistemática para que não acabem por acarretar um tratamento menos benéfico - na prática - para as pessoas com deficiência, contrariando a orientação legislativa e constitucional.

No caso do sistema das invalidades, deve o intérprete modular a nulidade ou a anulação do ato diante da situação concretamente analisada, verificando o grau de vulnerabilidade e discernimento em concreto da pessoa com deficiência intelectual ou psíquica no momento de praticar o ato. Deve-se, ainda, verificar se o ato e seus efeitos atendem ou não aos valores do ordenamento, realizando-se um controle de merecimento de tutela.

Em outras palavras: cabe ao intérprete, diante de cada situação individualmente considerada, verificar se a pessoa com deficiência possuía condições para o exercício de sua autonomia, ou seja, se possuía discernimento para a prática daquele ato em específico, e se os efeitos desse ato se encontram em consonância com os valores resguardados pelo ordenamento jurídico, quais sejam: a proteção da parte vulnerável e a promoção, em condições de igualdade, do exercício dos direitos e das liberdades fundamentais pelas pessoas com deficiência, visando à sua inclusão social e cidadania, como previsto pelo art. $1^{\circ}$ do EPD.

Com efeito, a modificação do texto legal, por si só, não basta para que se mude a perspectiva sobre a pessoa com deficiência: é preciso buscar a efetiva concretização das orientações da Convenção e do EPD, o que perpassa pela releitura também de categorias antes estanques e abstratas, como o regime de capacidades e invalidades.

\section{Referências}

ABREU, Célia Barbosa. A curatela sob medida: notas interdisciplinares sobre o estatuto da pessoa com deficiência e o novo CPC. In: MENEZES, Joyceane Bezerra de (org.). Direito das pessoas com deficiência psíquica e intelectual nas relações privadas: convenção sobre os direitos das pessoas com deficiência e Lei Brasileira de Inclusão. Rio de Janeiro: Processo, 2016. p. 545-568.

ABREU, Célia Barbosa. Capacidade civil, discernimento e dignidade do portador de transtorno mental. Revista Brasileira de Direito das Famílias e Sucessões, Belo Horizonte, ano 10, n. 8, p. 5-18, fev./ mar. 2009.

ABREU, Célia Barbosa; MANUEL, Eduardo. A flexibilização da curatela para o psicopata: uma interpretação constitucional pelo Superior Tribunal de Justiça. Revista da AJURIS, Rio Grande do Sul, v. 41, n. 134, p. 109-133, 2014.

ALMEIDA, Vitor. A capacidade civil das pessoas com deficiência e os perfis da curatela. Belo Horizonte: Fórum, 2019. 
ARIÈS, Philippe; DUBY, Georges. História da vida privada: do Império Romano ao ano mil. São Paulo: Companhia das Letras, 2009. v. 1.

BARBOZA, Heloisa Helena. A pessoa na era da biopolítica: autonomia, corpo e subjetividade. Cadernos IHU ideias, Rio Grande do Sul, ano 11, n. 194, p. 3-20, 2013.

BARBOZA, Heloisa Helena. Curatela do enfermo: instituto em renovação. In: MONTEIRO FILHO, Carlos Edison do Rêgo; GUEDES, Gisela Sampaio da Cruz; MEIRELES, Rose Melo Venceslau (org.). Coleção direito UERJ 80 anos: direito civil. Rio de Janeiro: Freitas Bastos, 2015. v. 2, p. 433-451.

BARBOZA, Heloisa Helena. Curatela em nova perspectiva. In: SÁ, Maria de Fátima Freire de; NOGUEIRA, Roberto Henrique Pôrto; SCHETTINI, Beatriz. Novos direitos privados. Belo Horizonte: Arraes Editores, 2016. p. 85-97.

BARBOZA, Heloisa Helena; ALMEIDA JUNIOR, Vitor de Azevedo. A (in) capacidade da pessoa com deficiência mental ou intelectual e o regime das invalidades: primeiras reflexões. In: EHRHARDT JR., Marcos (coord.). Impactos do novo CPC e do EDP no direito civil brasileiro. Belo Horizonte: Fórum, 2016. p. 205-227.

BARBOZA, Heloisa Helena; ALMEIDA, Vitor. O novo perfil da curatela em face do Estatuto da Pessoa com Deficiência. In: CABANELLAS, Beatriz Ramos; SILVA, Juvêncio Borges (coord.). Direito de família e sucessões. Florianópolis: CONPEDI, 2016. p. 128-147.

DIDIER JR., Fredie. Editorial 187: Estatuto da Pessoa com Deficiência, Código de Processo Civil de 2015 e Código Civil: uma primeira reflexão. Fredie Didier Jr., Salvador, 06 ago. 2015. Disponível em: http://www.frediedidier.com.br/editorial/editorial-187/. Acesso em: 30 ago. 2019.

FARIAS, Cristiano Chaves de; ROSENVALD, Nelson. Curso de direito civil: famílias. 8. ed. Salvador: JusPodivm, 2016.

FERNANDES, Micaela Barros Barcelos; GONÇALVES, Marcos Alberto Rocha. Curatela: da estrutura formal binária à construção funcional da autonomia e da dignidade. In: TEPEDINO, Gustavo; OLIVA, Milena Donato (coord.). Teoria geral do direito civil: questões controvertidas. Belo Horizonte: Fórum, 2019. p. 39-65.

LAGO JÚNIOR, Antonio; BARBOSA, Amanda Souza. Primeiras análises sobre o sistema de incapacidades, interdição e curatela pós Estatuto da Pessoa com Deficiência e Código de Processo Civil de 2015. Revista de Direito Civil Contemporâneo, São Paulo, v. 8, n.1, p. 49-89, jul./set. 2017.

LIMA, Taisa Maria Macena de; VIEIRA, Marcelo de Mello; SILVA, Beatriz de Almeida Borges. Reflexões sobre as pessoas com deficiência e sobre os impactos da Lei $n^{\circ} 13.146 / 2015$ no estudo dos planos do negócio jurídico. Revista Brasileira de Direito Civil, Belo Horizonte, v. 14, n.1, p. 17-39, out./dez. 2017.

MEIRELES, Rose Melo Vencelau. Autonomia privada e dignidade humana. Rio de Janeiro: Renovar, 2009.

MENEZES, Joyceane Bezerra de. A capacidade jurídica pela Convenção sobre os Direitos da Pessoa com Deficiência e a insuficiência dos critérios do status, do resultado, da conduta e da funcionalidade. In: TEPEDINO, Gustavo; OLIVA, Milena Donato (coord.). Teoria geral do direito civil: questões controvertidas. Belo Horizonte: Fórum, 2019. p. 67-89.

MENEZES, Joyceane Bezerra de. O direito protetivo no Brasil após a convenção sobre a proteção da pessoa com deficiência: impactos do novo CPC e do estatuto da pessoa com deficiência. Civilistica. com, Rio de Janeiro, ano 4, n. 1, p. 1-34, jan./jun. 2015. Disponível em: http://civilistica.com/o-direitoprotetivo-no-brasil/. Acesso em: 27 jun. 2017.

MENEZES, Joyceane Bezerra de. Tomada de decisão apoiada: instrumento de apoio ao exercício da capacidade civil da pessoa com deficiência instituído pela Lei Brasileira de Inclusão (Lei n. 13.146/2015).

Revista Brasileira de Direito Civil, Belo Horizonte, v. 9, n.1, p. 31-57, jul./set. 2016.

NEVARES, Ana Luiza Maia; SCHREIBER, Anderson. Do sujeito à pessoa: uma análise da incapacidade civil. In: TEPEDINO, Gustavo; TEIXEIRA, Ana Carolina Brochado; ALMEIDA, Vitor (coord.). O Direito 
civil entre o sujeito e a pessoa: estudos em homenagem ao professor Stefano Rodotà. Belo Horizonte: Fórum, 2016. p. 39-56.

PALACIOS, Agustina. El modelo social de discapacidad: orígenes, caracterización y plasmación en la Convención Internacional sobre los Derechos de las Personas con Discapacidad. Madrid: Ediciones CINCA, 2008.

PEREIRA, Caio Mário da Silva. Instituições de direito civil: Introdução ao direito civil. Teoria geral do direito civil. 31. ed. Rio de Janeiro: Forense, 2018. v. 1.

ROSENVALD, Nelson. Curatela. In: PEREIRA, Rodrigo da Cunha (org.). Tratado de direito das famílias. 2. ed. Belo Horizonte: IBDFAM, 2016. p.743-824.

SIMÃO, José Fernando. Estatuto da pessoa com deficiência causa perplexidade: parte 1. Conjur, São Paulo, 6 ago. 2015. Disponível em: https://www.conjur.com.br/2015-ago-06/jose-simao-estatuto-pessoadeficiencia-causa-perplexidade. Acesso em: 16 fev. 2019.

SOUZA, Eduardo Nunes de. Teoria geral das invalidades do negócio jurídico: nulidade e anulabilidade no direito civil contemporâneo. São Paulo: Almedina, 2017.

SOUZA, Eduardo Nunes de. Uma releitura funcional das invalidades do negócio jurídico: proposta de modulação dos efeitos de atos nulos e anuláveis. Civilistica.com, Rio de Janeiro, ano 6, n. 1, p. 1-48, 2017. Disponível em: http://civilistica.com/uma-releitura-funcional-das-invalidades/. Acesso em: 16 fev. 2019.

SOUZA, Eduardo Nunes de; SILVA, Rodrigo da Guia. Autonomia, discernimento e vulnerabilidade: estudo sobre as invalidades negociais à luz do novo sistema das incapacidades. Civilistica.com. Rio de Janeiro, ano 5, n. 1, p. 1-37, 2016. Disponível em: http://civilistica.com/autonomiadiscernimento-evulnerabilidade/. Acesso em: 03 dez. 2018.

SOUZA, Eduardo Nunes de; SILVA, Rodrigo da Guia. Discernimento da pessoa humana e sua relevância para o regime jurídico da prescrição e da decadência. In: BARBOZA, Heloisa Helena; MENDONÇA, Bruna Lima de; ALMEIDA JÚNIOR, Vitor de Azevedo (coord.). O código civil e o estatuto da pessoa com deficiência. Rio de Janeiro: Processo, 2017. p. 99-166.

TEPEDINO, Gustavo; OLIVA, Milena Donato. Personalidade e capacidade na legalidade constitucional. In: MENEZES, Joyceane Bezerra de (org.). Direito das pessoas com deficiência psíquica e intelectual nas relações privadas: convenção sobre os direitos das pessoas com deficiência e Lei Brasileira de Inclusão. Rio de Janeiro: Processo, 2016. p. 227-247.

Recebido em: 01/07/2020

Aprovado em: 20/07/2020 